\title{
Editorial
}

\section{Entrepreneurial ecosystems: Founding figures and research frontiers in economic geography}

https://doi.org/10.1515/zfw-2019-0008

Submitted: 16. March 2019; accepted: 23. September 2019

\begin{abstract}
The editorial for the special issue on entrepreneurial ecosystems summarizes the ongoing debate on the entrepreneurial ecosystem concept and portrays the backgrounds of founding figures of the concept. It traces the unique contribution of this issue with regard to recently published research. The contributions deal with the measurement of and the role of specific actors and institutions in entrepreneurial ecosystems.
\end{abstract}

Keywords: entrepreneurial ecosystem, review, economic geography

\section{Introduction}

Over the past ten years, the concept of entrepreneurial ecosystems has received a great deal of resonance not only in business, management and, entrepreneurship studies, but also in economic geography. Entrepreneurial ecosystems are a 'conceptual umbrella for the benefits and resources produced by a cohesive, typically regional, community of entrepreneurs and their supporters that help new highgrowth ventures form, survive, and expand' (Spigel and Harrison, 2018, p. 152). According to Malecki’s analysis (2018) over the past two years in particular the number of published papers have increased significantly. When this period is compared to the period from the 1980s to 2000s, it is clear to see that the number of scientific publications referring to entrepreneurial or start-up ecosystems has risen from below 10 papers per year to 139 (Source: Scopus) respectively 69 papers (Source: Web of Science) for 2016 and 2017 (Malecki, 2018, p. 2). The popularity of the entrepreneurial ecosystem approach seems to be

\footnotetext{
*Corresponding Author: Susann Schäfer, Friedrich Schiller University Jena, Institute of Geography, Löbdergraben 32, 07743 Jena, Germany, e-mail: susann.schaefer@uni-jena.de Heike Mayer, University of Bern, Institute of Geography \& Center for Regional Economic Development, Bern, Switzerland, e-mail: heike.mayer@giub.unibe.ch
}

based on the universal applicability with regard to different regional and industrial contexts. At the same time, the approach represents a holistic framework and pays attention to the entrepreneurial environment - a perspective that has been lacking in management and entrepreneurship studies. For economic geographers, the concept does indeed add something new to established concepts of industrial organization, such as the industry cluster approach (Porter, 2000), by highlighting the role of specific actors (especially the entrepreneur) and by mitigating aspects that these traditional concepts often overemphasize and view certain aspects as crucial (e. g., the specifics of the industry). Whereas the ecosystem approach emphasizes the role of the social and economic context surrounding the entrepreneurial process, more traditional concepts (Industrial District, Cluster, Innovation System) regard startups as smaller versions of larger, international firms and not as unique organizational entities with different (and often more constrained) capabilities and resources (Stam and Spigel, 2016, p. 3). Against this background, an increasing number of scholars favor the entrepreneurial ecosystem approach when focusing on startup entrepreneurship - not because other concepts do not consider them at all, but due to the more specific vantage point on entrepreneurial processes. Thus, Stam and Spigel (2016) suggest that the entrepreneurial ecosystem approach does not replace existing concepts of industrial organization but adds a specific value with regard to entrepreneurship.

The 'Zeitschrift für Wirtschaftsgeographie' now contributes to the ongoing theoretical ramifications of the entrepreneurial ecosystem concept with a special issue on theorizing entrepreneurial ecosystems. Whereas three papers focus on concepts and methodologies of measuring entrepreneurial ecosystems, two papers deals with actors and institutions in entrepreneurial ecosystems. Although each paper elaborates on its specific contribution to the further development of theory, this editorial seeks to introduce its readers to the discourse on entrepreneurial ecosystems, to outline recent research frontiers, and to present its papers.

Unlike the review articles that have dealt with the discursive lineages of the entrepreneurial ecosystem 
concept before (Acs et al., 2017; Alvedalen and Boschma, 2017; Audretsch et al., 2018; Malecki, 2018; Stam, 2015), our summary highlights the educational backgrounds and contributions of academics who can be considered as founding figures of the entrepreneurial ecosystem approach. Although this focus on biographies is unusual and certainly incomplete, we hope to shed some light on the ways in which the concept emerged in various disciplines and how it ultimately became prominent in economic geography. This historical overview is followed by a characterization of the status quo of the research frontiers. We identify four theoretical strands of the discussion: i) the evolution of entrepreneurial ecosystems, ii) the relational aspects and interconnectedness of actors and organizations, iii) the metrics of entrepreneurial ecosystems, and iv) the specific roles and spaces in entrepreneurial ecosystems. We then summarize each theoretical strand. Following this discussion, we shortly outline the contribution of the five articles of this issue and link them to the theoretical strands we identified. Finally, this editorial concludes with a summary of major findings.

\section{Founding figures of the entrepreneurial ecosystem approach}

Every academic discourse is characterized by several figures that have written key publications that are often disproportionately cited. We decided to adopt a biographical perspective to illustrate the evolution of the entrepreneurial ecosystem approach. Although such a perspective is far from complete and is prone to omissions - most notably regarding the key figures' motivation to write about entrepreneurial ecosystems, the biographical perspective can help us to understand the ways in which the concept entered the field of economic geography. Early key publications around the concept of entrepreneurial ecosystems focused predominantly on policy because the concept was perceived as a practical tool to support high-growth entrepreneurship (ranging from large-scale initiatives of the European Union to national policies, e.g. regional networks based on the ecosystem-approach to support the local start-up scene). In fact economic geography scholars only started to work on the concept in later phases.

The founding figures of the entrepreneurial ecosystem approach that we selected are based on the number of citations in the Web of Science, Scopus and Google Scholar as published and reviewed by Malecki $\left(2018^{1}\right)$. In this publication, Malecki reviews the evolution of the concept but does not cover the backgrounds of the key scholars. We do acknowledge that these founding figures have not developed their contributions 'out of the blue' but that their thinking has been influenced by important works on entrepreneurship and its regional environment back in the 1990s (for example, Malecki, 1997; Moore, 1999; Neck et al., 2004; Spilling, 1996). We are also aware that this approach discriminates critical publications on entrepreneurial ecosystems that have been published in the past two years given that they have not had the same amount of time to achieve an equivalent citation frequency. This phase also benefitted from a concerted effort on behalf of the US-based Ewing Marion Kauffman Foundation to promote research on entrepreneurial ecosystems in fields such as urban studies and economic geography. There are various limitations to our approach, which cannot be rectified in this short editorial. However, we acknowledge that the following review is incomplete particularly in terms of the motivations and interests of the writers and the particularities of their disciplines, life experiences, etc. that may have influenced them. Such a perspective is particularly interesting given the emergence of particularly prominent concepts in economic geography and there is a large research gap regarding the concepts genesis, which cannot be filled with a bibliographic approach and which exceeds the scope of this editorial.

Based on Malecki's assessment (2018), the founding figures are Brad Feld, Boyd Cohen, Daniel Isenberg, Colin Mason, Ross Brown, and Erik Stam. Our review portrays two phases of the entrepreneurial ecosystem debate that differ according to the regional and disciplinary scopes of the debate. In the first phase (2006-today), management and entrepreneurship scholars in the United States and Canada promoted and coined the entrepreneurial ecosystem approach (Cohen, Isenberg, and Feld). The focus here is on Cohen's article 'Sustainable valley entrepreneurial ecosystem' (2006), Isenberg's entrepreneurial ecosystem model that was published in several releases (2010, 2011), and the book 'Startup communities' by Brad Feld (2012). In the second phase (2013-today), this approach was adopted by scholars in Europe (Mason, Brown, and Stam). For the debate in Europe Mason and Brown's OECD report 'Entrepreneurial ecosystems and growth oriented entrepreneurship' (2014) was crucial as was Stam's article 'Entrepreneurial ecosystems and regional policy: a sympathetic critique' (2015).

1 We considered only those publications that referred to ,entrepreneurial ecosystem' or Entrepreneurial AND ecosystem. 


\section{First phase: Adoption of the entrepreneurial ecosystem approach in management and entrepreneurship studies in the United States}

The founding figures of the entrepreneurial ecosystem concept have a background in management and entrepreneurship studies in the United States. Whereas Cohen and Isenberg have pursued academic careers in those academic fields, Feld is an alumni of the MIT who became an IT entrepreneur, investor, and adviser in a start-up ecosystem (Boulder, Colorado). From his practical experience in those roles, he became an expert on how to build a specific entrepreneurial ecosystem: the start-up ecosystem. The fact that the concept gained so much popularity in the United States has much to do with the close relationship of the writers at that time with specific regions and policymakers. Also, their own experience as entrepreneurs in a specific region that was at that time characterized by high rates of startup activities helped them not only to describe a regional entrepreneurial ecosystem, but also to popularize the concept. This popularization can be seen as critical because the concept suffered similar criticism to other concepts before it (e.g. creative class or clusters, see also Martin and Sunley, 2003; Peck, 2005). Nevertheless, these writings influenced the academic discourse and helped pave the way for more rigorous research in the second phase.

One of the first writings on the concept was developed by Boyd Cohen, who obtained his Ph.D. in business strategy and entrepreneurship from the University of Colorado in 2001. After moving to the University of Victoria, Canada, in 2004, Cohen co-authored the article 'An Entrepreneurial System View of New Venture Creation"2 and authored the paper 'Sustainable valley entrepreneurial ecosystems' (Cohen, 2006) in the journal 'Business Strategy and the Environment'. This article is now one of the most cited publications on entrepreneurial ecosystems. Whereas the 2004 paper is an entrepreneurial genealogy study of the entrepreneurial ecosystem in Boulder County, Colorado, Cohen extended the entrepreneurial ecosystem perspective on a theoretical level with regard to sustainable innovations in his second paper (2006). In this publication, the local community is conceptualized as the center for entrepreneurial innovations. He introduced a novel type

2 Cohen's coauthors were Heidi Neck, then an assistant professor of entrepreneurship at Babson College, a private business school in Wellesley, Massachusetts, G. Dale Meyer, professor of entrepreneurial development at the University of Colorado-Boulder, and Corbett, an assistant professor at Rensselaer Polytechnic Institute. of entrepreneurial ecosystem, the 'sustainable entrepreneurial ecosystem', to apply the observed entrepreneurial ecosystem components to ecological concepts, such as environmental sustainability. Cohen's interest in entrepreneurship in combination with sustainability has continued until today (EADA, 2018), although the entrepreneurial ecosystem approach has not remained a prominent concept in his recent publications. The specification of the 'sustainable entrepreneurial ecosystem' has, only resonated selectively however in the academic community (Theodoraki, Messeghem and Rice, 2018).

The second most widely published and cited piece of work is Isenberg's descriptive classification of the entrepreneurial ecosystem (2011). Daniel Isenberg was awarded his PhD in social psychology by Harvard University. In the 1980s and 2000s he taught at the Harvard Business School, first in organizational behavior and later in entrepreneurial management. Isenberg's publication became popular, not because it was radically innovative (key aspects of this model have already been published by other scholars), but because it was the first comprehensive, yet still descriptive collection of all possibly relevant ecosystem elements. This also allowed him to build a close relationship with the entrepreneurial community that also benefitted from his teachings. At Babson Executive Education, Daniel Isenberg set up and manages a 3-day program called 'Driving Economic Growth Through Entrepreneurship Ecosystems', aimed at regional publicand private-sector leaders (Babson College, 2018) where participants learn in practical ways how to establish and scale up their entrepreneurial ecosystem. Thus, the more descriptive focus on the concept is understandable.

The third founding figure of the entrepreneurial ecosystem concept is Brad Feld, an entrepreneur who holds a Bachelor of Science and Master of Science in management from the Massachusetts Institute of Technology (Feld, 2012, p. 189). He became an entrepreneur and later invested in and mentored other startups (e.g. he co-founded Techstars, a startup accelerator). He started his career in Boston and moved to Boulder in 1995. In Boulder, he experienced a thriving entrepreneurial ecosystem, in which entrepreneurs like himself, not only engaged in their own entrepreneurial success but also in that of the region. Several years later in 2012, he published his well-known book 'Startup communities - Building an entrepreneurial ecosystem in your city', which is based on his experience as an investor and entrepreneur.

It is worth noting that all three founding figures were entrepreneurs, investors, and mentors of start-ups (Babson College, 2018; EADA, 2018; Feld, 2012) who cultivated close interactions between academia and practice through their 
applied work. Another interesting feature is the regional embeddedness of these founding figures. Whereas Cohen and Isenberg were based for a long time in Boulder, Colorado, respectively Boston, Feld was first educated and had worked in Boston before he moved to Boulder. Therefore, we can assume that the debate on entrepreneurial ecosystems first emerged and grew in those two specific regions. Their works were also influenced by the high levels of engagement in the entrepreneurial communities that they lived in.

The first phase of rather policy-oriented works was followed by significant efforts on behalf of the Ewing Marion Kauffman Foundation. This philanthropy-focused foundation has for a long time been interested in actively supporting entrepreneurship in its home region Kansas City (Mayer, 2012), but also in establishing research along the lines of minority group and women entrepreneurship or more recently (and very relevant for this discussion) the concept of the entrepreneurial ecosystem. Under the leadership of Dane Stangler and Yasuyuki Motoyama, the foundation started to fund research projects on entrepreneurial ecosystems in 2014. Back then 10 research projects were supported by scholars in the fields of urban planning, urban studies, and economic geography (e.g., Catherine T. Lawson, Elsie Harper-Anderson, Greg Schrock, Haifeng Qian, Marc Meyer, Murray Rice, Nichola Lowe, Ziona Austrian, Ingrid Gould Ellen, Cathy Liu). Kauffman launched a second round of requests for proposals in 2015/2016, resulting in another 8 to 10 projects. Moreover, in October 2015, the Foundation held a conference in Kansas City, at which some of the grant holders presented their research and discussed ways of analyzing, measuring, and theorizing entrepreneurial ecosystems. The conference helped researchers to establish a network not only from the United States but also from Europe (Colin Mason and Heike Mayer attended) and from a wide range of fields including urban planning, urban studies, and economic geography. The conference also helped develop new insights into the concept through, for example, co-authored publications (e. g., Mack and Mayer, 2016).

\section{Second phase: Emergence of the entrepreneurial ecosystem approach in Europe}

The popularity of the entrepreneurial ecosystem approach among policy actors spilled over to Europe where Colin Mason and Ross Brown drafted the paper 'Entrepreneurial Ecosystems and Growth oriented Entrepreneurship' for a workshop organized by the OECD LEED Programme and the Dutch Ministry of Economic Affairs on November $7^{\text {th }}$, 2013. Both Colin Mason and Ross Brown worked as expert advisers to the OECD and were invited to write that paper. Today, Ross Brown is a reader in management at the University of St. Andrews (University of St. Antdrews, 2018) and Colin Mason holds a professorship of entrepreneurship at the University of Glasgow. Both are members of the Enterprise Research Centre, the UK's leading centre for research on growth, innovation and productivity of small and medium-sized enterprises (SMEs). The workshop to which they contributed their paper took place in November 2013 in The Hague, the Netherlands. In Europe, the entrepreneurial ecosystem approach was first conceived as an economic policy to promote high growth firms. Two years after the OECD report, Erik Stam, a Dutch professor of strategy, organization and entrepreneurship published his key publication on 'Entrepreneurial Ecosystems and Regional Policy'. Whereas the Mason and Brown paper is a state-of-the art contribution without original theoretical input, Stam identifies shortcomings of the entrepreneurial ecosystem approach (Stam, 2015) and develops a new model stressing the upward and downward causation and intra-layer relations within an entrepreneurial ecosystem.

\section{Short discussion of the two phases}

The initial debates on entrepreneurial ecosystems had a strong focus on policy-making and particularly on questions about how cities and regions can develop into vibrant ecosystems or how high-growth enterprises can be supported within a specific regional context. Therefore, the empirical evidence - often anecdotal narratives from flourishing entrepreneurial regions - was less of an analytical attempt to measure ecosystems as such, but rather a selection of blue prints to foster high-growth entrepreneurship. This is the reason why scholarly demarcations to other concepts dealing with industrial organization in space (e. g., cluster, innovative milieus) were only elaborated at later stages of the debate, for example by Stam and Spigel (2016) or Spigel and Harrison (2018). In fact, several of the founding figures were not concerned with theoretical differentiations. Feld, for example, argued that what he called 'startup communities' is referred to as 'clusters' by academics (Feld, 2012, p. 1).

Since the publications of the founding figures, a range of scholars have published different definitions of and methodologies for examining entrepreneurial ecosystems (Acs et al., 2017; Alvedalen and Boschma, 2017; Audretsch and Belitski, 2017; Brown and Mason, 2017; Colombo et al., 2017; O'Connor et al., 2018; Spigel, 2017; Sternberg, 
2009). Despite the heterogeneity of approaches, there is consensus to interpret these systems as 'sets or relations of interconnected actors and organizations which support entrepreneurship in a specific region' (Isenberg, 2011). Today, the theoretical advancements of the entrepreneurial ecosystem debate are interdisciplinary covering the disciplines of economic geography (such as Elizabeth Mack, Edward Malecki, Heike Mayer, Ben Spigel, etc.), economics, and entrepreneurship studies (for both, David Audretsch, Erik Stam, Allan O'Connor). Given that all of them were socialized in different 'schools of thought' (Fleck, 1981), they have contributed their theoretical perspectives to the ecosystem debate. For example, Ben Spigel added relational aspects within entrepreneurial ecosystems (Spigel, 2013, 2017) influenced by his PhD mentor, Harald Bathelt, who is one of the main representatives of relational economic geography (Bathelt and Glückler, 2011). Scholars who have had a stronger focus on entrepreneurship and innovation, such as David Audretsch or Allan O'Connor, contributed among other aspects the notion of policy and framework conditions to the ecosystem debate (Audretsch, 2011; O’Connor and Roos, 2015).

\section{Topics and research frontiers of the entrepreneurial ecosystems debate: the status-quo, contributions of this issue, and future research}

Although some key authors have labeled the concept of entrepreneurial ecosystems as 'metaphor' in a recent editorial, a term which lacks an exact definition and is characterized by inconsistent conceptual foundations (Audretsch et al., 2018), we believe that the theoretical advancements and research frontiers in the field of entrepreneurial studies in general and specifically regarding the concept of entrepreneurial ecosystems are visible and sustainable despite their heterogeneity. Several empirical studies and conceptual advancements have helped to sharpen the definition of entrepreneurial ecosystems. While an in-depth discussion of these advancements exceeds the scope of this editorial, we highlight four topics that summarize different dimensions of the scientific debate on entrepreneurial ecosystem. We thereby link the contributions of this special issue to these topics.

\subsection{The evolution of entrepreneurial ecosystems}

A set of publications illustrates the ways in which entrepreneurial ecosystems evolve (Mack and Mayer, 2016; Schäfer and Henn, 2018). This research is inspired by evolutionary economic geography and more specifically by concepts such as the evolution of clusters (Mayer, 2011; 'OUP accepted manuscript', 2018; Menzel and Fornahl, 2010) or by the work carried out in relation to the evolution of industries (Klepper and Graddy, 1990). Mayer and Mack (2016), for example, trace the evolution of the Phoenix entrepreneurial ecosystem and link it to different phases. They identify theoretical elements but also policy responses for each phase and find that the examined entrepreneurial ecosystem (Phoenix, US) at the time of the study was still in its birth phase and had essential elements missing. Schäfer und Henn (2018) write about the Tel Aviv entrepreneurial ecosystem and also identify different stages based on the migration dynamics of entrepreneurs. They show how the migration of Jews from the United States to Israel was a critical factor in the emergence of the ecosystem in Tel Aviv and that the transnational ties to entrepreneurial ecosystems in the United States are an important characteristic of the Israeli ecosystem today. Both papers highlight the dynamic and evolutionary nature of entrepreneurial ecosystems. However, while these two studies remain rather specific in terms of their studied regions, there is still a need to develop more general theoretical insights into the evolution of entrepreneurial ecosystems. For example, there is a lack of knowledge about the evolution of the system and spatial characteristics, borders, etc. There is also research missing in terms of the ways in which the various elements of the system co-evolve and change depending on each other. Given that data sources have matured and that scholars can increasingly use larger and more complex data sets, such a systemic view of the evolution of entrepreneurial ecosystems is indeed possible. In addition, some scholars criticize the evolutionary approach for being fatalistic because in the life cycle model, according to Mack and Mayer, an entrepreneurial ecosystem can also decline. Roundy et al. (2018) go beyond a life cycle or stage model and adopt a complex system perspective of the evolution of entrepreneurial ecosystems. From this perspective, the actors and the system are seen as self-organizing and adaptable, but also geographically bound and operating on numerous levels. They summarize their perspective with the following definition: "An entrepreneurial ecosystem is a self-organized, adaptive, and geographically bounded community of complex agents operating at multiple, aggregated levels, 
whose non-linear interactions result in the patterns of activities through which new ventures form and dissolve over time" (Roundy, Bradshaw and Brockman, 2018). Such a complexity oriented view is taken up in Spigel and Harrison's (2018) process theory of entrepreneurial ecosystems, in which they call for an adaptive and process-oriented perspective of these systems. Open questions regarding the evolution of entrepreneurial ecosystems are particularly concerned with unsuccessful entrepreneurial ecosystems. So far, studies have been biased towards rather successful and well-functioning regions and we lack insights into the ways in which ecosystems fail, why they fail, how they may be rejuvenated, and/or how policy might be able to influence their trajectories.

Although the evolution of entrepreneurial ecosystems has developed as a substantial topic in the debate, none of the contributions of the special issue are linked primarily to this topic. Nevertheless, we believe that this topic is a major line of discourse within the entrepreneurial ecosystem debate.

\subsection{The relational aspects and interconnectedness of actors and organizations}

Although Isenberg's model (2011) made clear which actors and dimensions an entrepreneurial ecosystem is composed of, little contributions have been made regarding the nature and dynamics of internal and external relations at the beginning of the debate. For several years now, scholars have contributed to the conceptualization of those relations and interconnections, mainly by importing theories from various social sciences. One such contribution is Ben Spigel's consideration of Bourdieu's concept of different forms of capital (cultural, social, and material) (2017). Spigel classifies ecosystem actors and dimensions according to those three forms and explains in a qualitative way how those capital forms relate to each other. Another approach to conceptualize the relations and connections within entrepreneurial ecosystems is based on network theories, such as business networks and system approaches (Daniel et al., 2018; Roundy, Bradshaw and Brockman, 2018). Although the concepts of business networks and in general system approaches can be both qualitative and quantitative, they have a strong link to the question about how the relations and connections can be measured (see section 3.3). A current research frontier with regard to the theorization (not measurement) of connections and relations is the lack of the temporary dimension of building, maintaining, and unlinking connections:
Current perceptions on relations and interconnections are rather static and do not account for their ephemerality. Approaches of current practice theory may be a potential theoretical contribution to bridge that gap (Gartner et al., 2016).

In this special issue, the paper 'Entrepreneurial ecosystems as issue, exchange or strategic action fields? Integrating meso-level institutional theory' by Carolin Auschra, Thomas Schmidt, and Jörg Sydow is a contribution to the theorization of the structure and agency of entrepreneurial ecosystems. The authors conceptualize entrepreneurial ecosystems as organizational fields (Auschra, Schmidt and Sydow, 2019), paying attention to the attributes of ecosystems as well as to the resources and institutions that influence actor's behavior. Their contribution to the debate is a stronger consideration of formal and informal institutions that enable and constrain entrepreneurial activity and interactions. Given that field theory is inherently processual, Auschra et al. add relevant theoretical insights into the dynamics of entrepreneurial ecosystems that are often taken for granted.

\subsection{The metrics of entrepreneurial ecosystems}

The initial descriptive studies of entrepreneurial ecosystems as highlighted earlier for first phase greatly relied on anecdotal and descriptive data. As the concept matured and as different data sources became available, the metrics and methodologies to study entrepreneurial ecosystems also developed. Credit et al. (2018) review available data at different scales and points out future directions. The paper presents a useful overview of the various data sources, their level of analysis and the metrics used. This review remains rather static however, as it merely lists data sets and their usefulness to study different aspects of entrepreneurial ecosystems. Similarly, Stam (2018) develops a set of indicators for entrepreneurial ecosystems and relates them to each other through correlation and regression analyses, developing an index. However, publications that illustrate how entrepreneurial ecosystems could be quantitatively measured and compared leave open questions regarding the complex, evolutionary nature of ecosystems. These questions are addressed by Roundy et al. (2018) who describe how for example qualitative comparative analysis or agent-based modelling and optimization could help to identify entrepreneurial dynamics that are highly complex and interrelated. Furthermore, efforts such as the longitudinal study of specific regions (e.g. the Research Triangle region in North Carolina, see also 
the work by Feldman and Lowe, 2015) are seldom because they depend on a long-term perspective, which requires setting up large-scale databases and continuous qualitative and quantitative observations.

For this special issue, the authors Nadina Iacob, Nicolas Friederici, and Jan Lachenmayer have developed an indicator-based framework to measure urban entrepreneurial ecosystems. In their paper 'Operationalising relational theory of entrepreneurial ecosystems at city-level in Africa, Asia and the Middle East', they develop and apply an index in eleven middle-income cities (Iacob, Friederici and Lachenmayer, 2019). Based on the premise that common aggregation methods (e.g., the arithmetic mean) fail to convey the interdependence of ecosystem components, Iacob et al.'s study explores the potential of the geometric mean as an alternative approach. Their analysis shows that this method renders more plausible results than the arithmetic mean because they operationalize complementarity between components more directly by introducing stronger penalties for imbalances in the ecosystem.

Whereas Iacob et al.'s paper focuses on the city level, a second paper in this issue refers to the regional scale: 'A new framework to measure entrepreneurial ecosystems at the regional level' by Rolf Sternberg, Johannes von Bloh and Alicia Coduras (2019) propose an entrepreneurial ecosystem index based on subnational indices as a method to measure and compare the performance of entrepreneurial ecosystems. Their contribution lies in the provision of a robust empirical measurement of various entrepreneurial ecosystems in order to improve the quality of the ecosystem definition which has often been criticized as vague and fuzzy.

\subsection{The specific roles and spaces in entrepreneurial ecosystems}

A very recent research frontier is the question regarding the role and contribution of ecosystem actors who are not entrepreneurs. Although Isenberg describes a multitude of different actors and organizations, scholars have only recently turned towards the empirical examination of those actors and organizations. While investors, advisors, and mentors have been neglected in the current entrepreneurial ecosystem debate (except for Feldman and Zoller, 2012), the roles of universities (Audretsch and Link, 2017; O'Connor and Reed, 2018) and the government (Colombo et al., 2017; Igwe, 2016) are covered well. Moreover, the contributions to but also the spaces of innovation and entrepreneurship in entrepreneurial ecosystems such as accelerators and incubators have found little resonance in the current debate although we are aware that in the late 1990s and early 2000s there was a vivid debate of those spaces without reference to the entrepreneurial ecosystem debate (Colombo and Delmastro, 2002; Scillitoe and Chakrabarti, 2010). With regard to the ecosystem concept, the question is not only how accelerators support entrepreneurship but how they are embedded in the entrepreneurial ecosystem and linked to other actors besides entrepreneurs. Goswami et al. (2018) were some of the first contributors to those questions which were studied in a vibrant IT ecosystem (Bangalore).

The paper 'From territorial to topological conceptions of entrepreneurial ecosystems: The dynamic spatiality of knowledge brokering in seed accelerators' in this special issue, written by Andreas Kuebart and Oliver Ibert (2019), extends Goswamit et al.'s perspective by focussing on knowledge transfers in those specific ecosystem spaces. Using process-based, qualitative case studies on seed accelerators from four regions, their study seeks to explore knowledge brokering in entrepreneurial ecosystems and analyzes the corresponding spatial dynamics. Key findings are that startups in digital fields share knowledge about business models and technologies in a way that is not attainable in classical knowledge clusters and that entrepreneurial practices rely on extra-regional resources.

The final paper of this special issue 'Applying the concept of entrepreneurial ecosystems in Estonia' by Merli Reidolf, Merle Küttim, Aleksandr Michelson, Helena Rozeik, and Marianne Kallaste (2019) addresses the question whether entrepreneurial ecosystems can be classified according to actors and organizations to identify regional subtypes of entrepreneurial ecosystems. Using the case study of Estonia, they demonstrate that regional entrepreneurial ecosystems are characterized through the components that exist at country level. With their paper, they make an important contribution to the question of how entrepreneurial ecosystems of different geographical scale are related.

\section{Conclusion}

The goal of this editorial was to give the readers of this special issue a short but informative overview of the founding figures of the entrepreneurial ecosystem approach and to contextualize the issue's contributions within the entrepreneurial ecosystem debate. Unlike other state-ofthe-art summaries, this editorial looks at the biography perspective of the founding figures of the entrepreneurial ecosystem concept, hoping that such a vantage point will 
help to understand how and why the ecosystem debate has emerged and unfolded as it has over the past decade. Besides the biography perspective, the current debate and research frontiers were classified around four topics where we see the strongest potential for further theoretical advancements - particularly for the field of economic geography. The fact that this special issue is only one contribution in the ongoing academic exchange of ideas and that the discussions will continue is reflected in the upcoming special issues and in the further publication of edited books.

\section{References}

Acs, Z.J. et al. (2017) 'The lineages of the entrepreneurial ecosystem approach', Small Business Economics, 49(1), pp. 1-10. doi: 10.1007/s11187-017-9864-8

Alvedalen, J. and Boschma, R. (2017) 'A critical review of entrepreneurial ecosystems research: Towards a future research agenda', European Planning Studies, 25(6), pp. 887-903. doi: 10.1080/09654313.2017.1299694

Audretsch, D.B. and Belitski, M. (2017) 'Entrepreneurial ecosystems in cities: Establishing the framework conditions', The Journal of Technology Transfer, 42(5), pp. 1030-1051. doi: 10.1007/ s10961-016-9473-8

Audretsch, D.B. and Link, A.N. (eds.) (2017) Universities and the entrepreneurial ecosystem. Cheltenham, UK: Edward Elgar Publishing.

Audretsch, D.B. (ed.) (2011) Handbook of Research on Innovation and Entrepreneurship. Cheltenham, U.K: Edward Elgar Publishing.

Audretsch, D.B. et al. (2018) 'Entrepreneurial ecosystems: economic, technological, and societal impacts', The Journal of Technology Transfer. doi: 10.1007/s10961-018-9690-4

Auschra, C., Schmidt, T. and Sydow, J. (2019) 'Entrepreneurial Ecosystems as issue, exchange or strategic action fields? Integrating meso-level institutional theory', Zeitschrift für Wirtschaftsgeographie (2-3).

Babson College (2018) About Daniel Isenberg. Available at: http://www.babson.edu/executive-education/expandingentrepreneurship/beep/Pages/isenberg-daniel.aspx (Accessed: 15 November 2018).

Bathelt, H. and Glückler, J. (2011) The relational economy: Geographies of knowing and learning. Oxford: Oxford University Press.

Brown, R. and Mason, C. (2017) 'Looking inside the spiky bits: a critical review and conceptualisation of entrepreneurial ecosystems', Small Business Economics, 49(1), pp. 11-30. doi: $10.1007 / \mathrm{s} 11187-017-9865-7$

Cohen, B. (2006) 'Sustainable valley entrepreneurial ecosystems', Business Strategy and the Environment, 15(1), pp. 1-14. doi: $10.1002 /$ bse. 428

Colombo, M.G. and Delmastro, M. (2002) 'How effective are technology incubators?' Research Policy, 31(7), pp. 1103-1122. doi: 10.1016/S0048-7333(01)00178-0
Colombo, M.G. et al. (2017) 'The governance of entrepreneurial ecosystems’, Small Business Economics. doi: 10.1007/s11187017-9952-9

Credit, K., Mack, E.A. and Mayer, H. (2018) 'State of the field: Data and metrics for geographic analyses of entrepreneurial ecosystems', Geography Compass, 12(9), e12380. doi: 10.1111/ gec 3.12380

Daniel, L. et al. (2018) 'Deconstructing the Entrepreneurial Ecosystem Concept', in O'Connor, A. et al. (eds.) Entrepreneurial Ecosystems: Place-Based Transformations and Transitions. (International Studies in Entrepreneurship, 38). Cham: Springer International Publishing; Imprint; Springer, pp. 23-44.

EADA (2018) Boyd Derek Cohen. Available at: https://www.eada. edu/en/teaching-and-research/departments/strategy-leadership-and-people/boyd-derek-cohen (Accessed: 13 November 2018).

Feld, B. (2012) Startup communities: Building an entrepreneurial ecosystem in your city. Hoboken, N.J.: Wiley.

Feldman, M. and Lowe, N. (2015) 'Triangulating regional economies: Realizing the promise of digital data', Research Policy, 44(9), pp. 1785-1793. doi: 10.1016/j.respol.2015.01.015

Feldman, M. and Zoller, T.D. (2012) 'Dealmakers in Place: Social Capital Connections in Regional Entrepreneurial Economies', Regional Studies, 46(1), pp. 23-37. doi: 10.1080/00343404.2 011.607808

Fleck, L. (1981) Genesis and development of a scientific fact. Chicago: University of Chicago Press.

Gartner, W.B. et al. (2016) 'Entrepreneurship as practice: grounding contemporary practice theory into entrepreneurship studies', Entrepreneurship \& Regional Development, 28(9-10), pp. 813-816. doi: 10.1080/08985626.2016.1251736

Goswami, K., Mitchell, J.R. and Bhagavatula, S. (2018) 'Accelerator expertise: Understanding the intermediary role of accelerators in the development of the Bangalore entrepreneurial ecosystem', Strategic Entrepreneurship Journal, 12(1), pp. 117-150. doi: 10.1002/sej.1281

lacob, N., Friederici, N. and Lachenmayer, J. (2019) 'Operationalising relational theory of entrepreneurial ecosystems at city-level in Africa, Asia and the Middle East', Zeitschrift für Wirtschaftsgeographie (2-3).

Igwe, P. (2016) Entrepreneurial Ecosystem and the Role of Government in Promoting Entrepreneurship.

Isenberg, D. (2010) 'How to Start an Entrepreneurial Revolution', Harvard Business Review (June), 2010. Available at: https:// hbr.org/2010/06/the-big-idea-how-to-start-an-entrepreneurial-revolution.

Isenberg, D. (2011) The Entrepreneurship Ecosystem Strategy as a New Paradigm for Economic Policy: Principles for Cultivating Entrepreneurship: The Babson Entrepreneurship Ecosystem Project.

Klepper, S. and Graddy, E. (1990) 'The Evolution of New Industries and the Determinants of Market Structure', The RAND Journal of Economics, 21(1), p. 27. doi: 10.2307/2555491

Kuebart, A. and Ibert, O. (2019) 'From territorial to topological conceptions of entrepreneurial ecosystems: The dynamic spatiality of knowledge brokering in seed accelerators', Zeitschrift für Wirtschaftsgeographie (2-3).

Mack, E. and Mayer, H. (2016) 'The evolutionary dynamics of entrepreneurial ecosystems', Urban Studies, 53(10), pp. 2118-2133. doi: 10.1177/0042098015586547 
Malecki, E.J. (2018) 'Entrepreneurship and entrepreneurial ecosystems', Geography Compass, 12(3), e12359. doi: 10.1111/ gec3.12359

Martin, R. and Sunley, P. (2003) 'Deconstructing clusters: chaotic concept or policy panacea?' Journal of Economic Geography, 3(1), pp. 5-35. doi: 10.1093/jeg/3.1.5

Mason, C. and Brown, R. (2014) Entrepreneurial ecosystems and growth oriented entrepreneurship. The Hague.

Mayer, H. (2011) 'Evolution, innovation and entrepreneurship in emerging industries Introduction to the special issue', Geographica Helvetica, 66(4), pp. 230-232. doi: 10.5194/ gh-66-230-2011

Mayer, H. (2012) Entrepreneurship and Innovation in Second Tier Regions. Cheltenham, U.K: Edward Elgar Publishing.

Menzel, M.-P. and Fornahl, D. (2010) 'Cluster life cycles dimensions and rationales of cluster evolution', INDUSTRIAL AND CORPORATE CHANGE, 19(1), pp. 205-238.

O’Connor, A. and Reed, G. (2018) 'Theorizing the University Governance Role in an Entrepreneurial Ecosystem', in O’Connor, A. et al. (eds.) Entrepreneurial Ecosystems: Place-based Transformations and Transitions: Springer Verlag, pp. 81-100.

O'Connor, A. and Roos, G. (eds.) (2015) Integrating innovation: South Australian entrepreneurship systems and strategies. Adelaide: The University of Adelaide University of Adelaide Press. Available at: http://www.jstor.org/stable/10.20851/j. ctt1sq5xd5.

O’Connor, A. et al. (eds.) (2018) Entrepreneurial Ecosystems: Place-based Transformations and Transitions: Springer Verlag.

Peck, J. (2005) 'Struggling with the Creative Class', International Journal of Urban and Regional Research, 29(4), pp. 740-770. doi: 10.1111/j.1468-2427.2005.00620.x

Porter, M.E. (2000) 'Locations, clusters, and company strategy', in Clark, G.L., Feldman, M.P. and Gertler, M.S. (eds.) The Oxford handbook of economic geography. Oxford: Oxford Univ. Press, pp. 253-274.

Roundy, P.T., Bradshaw, M. and Brockman, B.K. (2018) 'The emergence of entrepreneurial ecosystems: $A$ complex adaptive systems approach', Journal of Business Research, 86, pp. 1-10. doi: 10.1016/j.jbusres.2018.01.032

Schäfer, S. and Henn, S. (2018) 'The evolution of entrepreneurial ecosystems and the critical role of migrants. A Phase-Model based on a Study of IT startups in the Greater Tel Aviv Area', Cambridge Journal Of Regions, Economy And Society.

Scillitoe, J.L. and Chakrabarti, A.K. (2010) 'The role of incubator interactions in assisting new ventures', TECHNOVATION, 30(3), pp. 155-167. doi: 10.1016/j.technovation.2009.12.002

Spigel, B. (2013) 'Bourdieuian approaches to the geography of entrepreneurial cultures', Entrepreneurship \& Regional Development, 25(9-10), pp. 804-818. doi: 10.1080/08985626 .2013 .862974

Spigel, B. (2017) 'The Relational Organization of Entrepreneurial Ecosystems', Entrepreneurship Theory and Practice, 41(1), pp. 49-72. doi: 10.1111/etap.12167

Spigel, B. and Harrison, R. (2018) 'Toward a process theory of entrepreneurial ecosystems', Strategic Entrepreneurship Journal, 12(1), pp. 151-168. doi: 10.1002/sej.1268

Stam, E. (2015) 'Entrepreneurial Ecosystems and Regional Policy: A Sympathetic Critique', European Planning Studies, 23(9), pp. 1759-1769. doi: 10.1080/09654313.2015.1061484

Stam, E. and Spigel, B. (2016) ‘Entrepreneurial Ecosystems', U.S.E. Discussion Paper Series (16-13), pp. 1-18.

Sternberg, R. (2009) 'Regional Dimensions of Entrepreneurship', Foundations and Trends? in Entrepreneurship, 5(4), pp. 211-340. doi: 10.1561/0300000024

Sternberg, R., Bloh, J. von and Coduras, A. (2019) 'A new framework to measure entrepreneurial ecosystems at the regional level', Zeitschrift für Wirtschaftsgeographie (2-3).

Theodoraki, C., Messeghem, K. and Rice, M.P. (2018) 'A social capital approach to the development of sustainable entrepreneurial ecosystems: an explorative study', Small Business Economics, 51(1), pp. 153-170. doi: 10.1007/s11187-017-9924-0

University of St. Antdrews (2018) Dr Ross Brown. Available at: https://www.st-andrews.ac.uk/management/aboutus/people/ academic/rossbrown/ (Accessed: 3 December 2018). 